\title{
Comparative Analysis of Ranging Protocols for Localization by UWB in Outdoor
}

\author{
Salick Diagne1, Thierry Val'2, Abdou Karim Farota1, Bouya Diop' ${ }^{1}$ \\ ${ }^{1}$ Laboratoire des Sciences de l'Atmosphère et des Océans, UFR SAT/UGB, Saint-Louis, Sénégal \\ ${ }^{2}$ Institut de Recherche en Informatique de Toulouse, Université de Toulouse, Blagnac, France \\ Email: salickdiagne@gmail.com, thierry.val@univ-tlse2.fr, abdou-karim.farota@ugb.edu.sn, bouya.diop@ugb.edu.sn
}

How to cite this paper: Diagne, S., Val, T., Farota, A.K. and Diop, B. (2018) Comparative Analysis of Ranging Protocols for Localization by UWB in Outdoor. Wireless Sensor Network, 10, 103-117. https://doi.org/10.4236/wsn.2018.105006

Received: June 25, 2018

Accepted: May 27, 2018

Published: May 30, 2018

Copyright (c) 2018 by authors and Scientific Research Publishing Inc. This work is licensed under the Creative Commons Attribution International License (CC BY 4.0).

http://creativecommons.org/licenses/by/4.0/ (c) (i) Open Access

\begin{abstract}
The rapid evolution of technology in the field of wireless telecommunications and micro components using MEMS technologies (Micro-electromechanical systems) has contributed to the expansion and rapid development of wireless sensor networks (WSN). This rapid development has contributed to the appearance of sensor and actuator networks (WSAN) or even to the Internet of Things with DL-IoT (Device Layer-Internet of Things). This rapid evolution of WSN is due to the enthusiasm generated by this last in industry and research. This new technology is used in several applications, particularly in the outdoor location of communicating nodes. The process of distance calculation between nodes (ranging) is a primordial phase for a precise location of these nodes. This paper presents the result of measurements does with three ranging protocols (TWR, TWR_Skew and SDS-TWR) implemented on DecaWiNo nodes. DecaWiNo nodes use the Ultra-Wide Band (UWB) radio links, proposed by the IEEE 802.15.4 standard amendment of the year 2007, which provides a high-performance ranging by ToF (Time of Flight) [1] [2]. The results are very promising with precision errors of the order of $50 \mathrm{~cm}$ over 20 meters.
\end{abstract}

\section{Keywords}

Outdoor Location, UWB, Ranging, ToF, TWR, DecaWiNo

\section{Introduction}

We notice in recent years, agriculture increasingly oriented towards a widespread use of new technologies. We no longer talk about the mechanization of agriculture, but rather a smart agriculture. This type of agriculture uses WSAN technology to improve crop yields, in particular by controlling the humidity 
level of the plants [3] or for a much more precise irrigation [4]. Its field of application also covers intrusion detection, or more recently the mobile target tracking, especially with military security.

Our goal is to use this technology in mobile target tracking but applied to agriculture for crop protection. This idea was born from an observation made from the destruction of crops in the paddy fields of West Africa, particularly those of Senegal.

Indeed, the destruction of agricultural crops by grain-eating birds has always been a fundamental problem, especially in West Africa. According to [5], these birds, such as quelea, the golden sparrows, village weaver with a strong beak, cause very serious damage that can be estimated each year to several hundred thousand tons. They attack rice, maize, sorghum and wheat by eating the mature and milky grains.

This is how we asked ourselves this fundamental question that guided our approach:

Why not use the advantages offered by this new technology (DL-IoT) to help these farmers to protect their crops without harming the birds?

However, to achieve this, one of the first functions that this network must accomplish is to be able to efficiently locate its own nodes. This first function of our network is also the subject of this document in which we make the comparative study of some protocols of distance calculation between nodes (ranging) by ToF based on the UWB, in order to find the best protocol suited for our application type.

This work emphasizes the metric performances of DecaWiNo nodes in outdoor. In fact, these performances were until then studied in indoor [6], thus this result obtained will complete the DecaWiNos metric study with the main protocols using the ToF for a more general use of these nodes (Indoor and Outdoor).

So, after this introduction, we will first present the most traditional ranging protocols namely TWR, TWR_Skew and SDS-TWR. In the following we will present in Section 3 titled Outdoor measurements, the material used for measurements in particular the DecaWiNos nodes, the procedures and measurement results of the various protocols as well as their interpretation. Then in Section 4, we will discuss the results obtained. And finally, the conclusion will allow us to emphasize the possibilities of using our results as well as the research perspectives arising from this work.

\section{The Ranging Protocols}

For most sensor and actuator network applications, the event detected by a node is useful only if the information about its geographical location is provided. For this, the network needs to locate its nodes. So many algorithms and localization techniques in outdoor have been developed. These algorithms and localization techniques use a variety of communication technologies, offering to users adapted location systems according to the criteria required by the different 
DL-IoT type applications. These criteria are often the range of communication, the transmission rate or the energy consumption. Technologies such as infrared, Bluetooth, Zigbee or UWB are used in this sense by localization systems.

The most frequent localization techniques in literature can be classified into two groups: Range-Free localization and Range-Based localization.

The Range-Free technique, like those of the DV-Hop family, is based on topology and connectivity information, assuming an isotropic network where the number of jumps between the nodes is proportional to their distance. But this solution is not very accurate (because of the malfunctions and the not guaranteed network connectivity).

The Range-Based localization, uses the distance (or angle) measured between two nodes (Ranging) to determine the position of a node.

There are several techniques to measure the distance (or angle) between two nodes: The Time of Flight (ToF), the Time Difference of Arrival (TDoA), the Angle of Arrival (AoA), and the Received Signal Strength Indicator (RSSI).

In ToF or ToA (Time of Arrival), we exploit the relationship between distance travelled by the signal and the time taken. For this technique, synchronization between transmitter and receiver is often required.

The TDoA uses the same principle as ToA with some differences to measure the distance between two close nodes. It uses the time difference taken by two signals sent by the same node and whose propagation speed is different. In general, we use ultrasound $\left(\mathrm{V} \simeq 340 \mathrm{~m} / \mathrm{s}\right.$ in air at $\left.15^{\circ} \mathrm{C}\right)$ or sound waves $\left(\mathrm{C} \simeq 3.10^{8}\right.$ $\mathrm{m} / \mathrm{s}$ ) to have this difference. This technique has drawbacks related to the energy consumption (because of the two signals emitted), the short range and its limited use in outdoor due to ultrasound for example.

The technique based on the AoA allows the location of a node by measuring the arrival angle of a signal. In this technique, the nodes measuring the angle are equipped with small antennas or ultrasonic receiver. The receiving node uses the arrival time or signal phase to calculate the arrival angle.

These ultrasonic antennas and receivers (imposing small distances between receiving nodes) constitute the major disadvantage in terms of cost and size for this method.

Finally, for the RSSI technique that uses the physical characteristic of the radio channel (the RSSI signal strength). In theory more the distance between two nodes increases more the signal is attenuated (the RSSI power indicator decreases). Thus, it is possible for a receiving node to calculate the distance that separates it from a transmitting node based on the power of the received signal. This method has an advantage over the cost since the nodes are already equipped with RF devices. But it is not very precise compared to other methods. Because of its sensitivity to noise, interference, asymmetry of the communication link (no-conformity of the RSSI), obstacles and types of antennas capable caused errors exceeding $50 \%$ of the range of the communication device [7].

Although requiring a perfect synchronism of the transmitting and receiving 
nodes, the technique based on the ToF is much more precise than the other techniques especially with the use of the UWB technology (ensuring an acceptable synchronization).

Thus, several works propose methods of distance calculation between nodes (Ranging) based on the ToF. These methods of calculation often called Ranging protocols are presented in the following sections.

\subsection{TWR (To Way Ranging)}

This is the simplest protocol using two-node messages and taking the clock from one of the nodes as a reference. Because most of the time, nodes in communication are often asynchronous. The TWR protocol is based on a set of three messages, two of which, (START and ACK) necessary for stamping and obtaining time-of-flight measurement information (Figure 1).

In this protocol, the node A, initiator of the exchange sends its first frame (START) and marks its time of emission $t_{1}$. On receipt of this frame, the node B in turn marks the reception time $t_{2}$ of this frame and after a certain time sends an acknowledgment frame (ACK) while marking its sending time $t_{3}$. The node A, on receipt of the ACK frame, marks the reception time $t_{4}$. The four time stamps are collected on the node A side after receiving the DATA_REPLY frame containing the tags $t_{2}$ and $t_{3}$ of the node B. This last frame will allow node A to calculate the flight time noted in Equation (1) and distance in Equation (2).

$$
\mathrm{ToF}_{\mathrm{TWR}}=\frac{\left(t_{4}-t_{1}\right)-\left(t_{3}-t_{2}\right)}{2}
$$

$$
\text { Distance }=\mathrm{ToF}_{\mathrm{TWR}} * C \text {, with } C \approx 3.10^{8}
$$

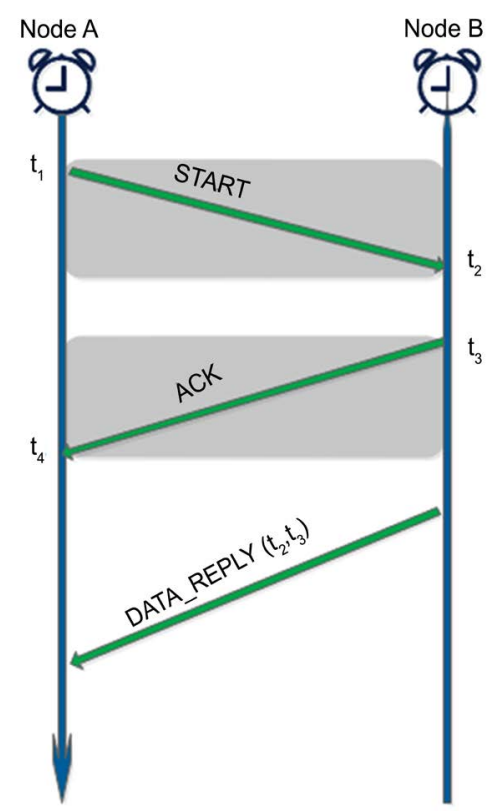

Figure 1. TWR protocol performing ToF measurement between two "asynchronous" nodes. 
The principal disadvantage of this protocol is the drift of the clocks which causes temporal imprecision. Indeed, the two clocks of the nodes A and B are not based on the same quartz, they cannot be perfectly synchronous. Thus, an overestimation or underestimation of the measurement of the flight time could lead to an absurd location of the nodes.

\subsection{TWR_Skew}

The TWR_Skew is a protocol based on the simple TWR, it is presented in [8]. Its objective was to evaluate the impact of TWR ranging accuracy in normal traffic by introducing a variable artificial delay in order to compensate for imprecision due to delay. This delay introduced between the messages START and ACK actually represents the delay introduced by the usual traffic especially the method of access to the medium.

The authors of [8] propose a correction of the introduced error, based on the parameter $k$ which represents the ratio of the frequency $f_{\mathrm{B}}$ of the clock of the node $\mathrm{B}$ and the frequency $f_{\mathrm{A}}$ of the clock of the node $\mathrm{A}$. By introducing this parameter $k$ into Equation (1), this results in a new general ToF equation:

$$
\mathrm{ToF}_{\mathrm{TWR} \_ \text {Skew }}=\frac{t_{4}-t_{1}-k\left(t_{3}-t_{2}\right)}{2}, \text { with } k \approx 1
$$

The communication modules that we use with DecaWiNo and also used in [8] offer functionality, the Clock Offset evaluating the difference in frequency between the two clocks. This difference called Skew is the origin of the name of this protocol.

It is affirmed in [8] that this correction makes it possible to correct both the drift errors introduced by the temperature variations and those due to delays between messages (Figure 2).

\subsection{The SDS-TWR Protocol (Symmetrical Double-Side Two-Way Ranging)}

In order to reduce or eliminate the error introduced by the clock drift, another protocol symmetries the ranging session by adding an additional message to the classical session of the TWR protocol: this is the SDS-TWR protocol.

1) The Double-sided component: The protocol is based on two symmetrical sessions of the TWR protocol $\left(\mathrm{TWR}_{\mathrm{A}-\mathrm{B}}\right.$ and $\left.\mathrm{TWR}_{\mathrm{B}-\mathrm{A}}\right)$.

$$
\begin{gathered}
\operatorname{TWR}_{\mathrm{A}-\mathrm{B}}: \operatorname{ToF}_{\mathrm{A}-\mathrm{B}}=\frac{\left(t_{4}-t_{1}\right)-\left(t_{3}-t_{2}\right)}{2} \\
\operatorname{TWR}_{\mathrm{B}-\mathrm{A}}: \operatorname{ToF}_{\mathrm{B}-\mathrm{A}}=\frac{\left(t_{6}-t_{3}\right)-\left(t_{5}-t_{4}\right)}{2}
\end{gathered}
$$

2) The Symmetrical component: the response time between the two nodes is assumed to be identical ( $T_{R-A}=T_{R-B}$, with $T_{R}=$ Response Time) (Figure 3).

Each node marks its own transmit and receive stamps. All the timestamps will be collected on the side of the node A after the reception of the DATA_REPLY 


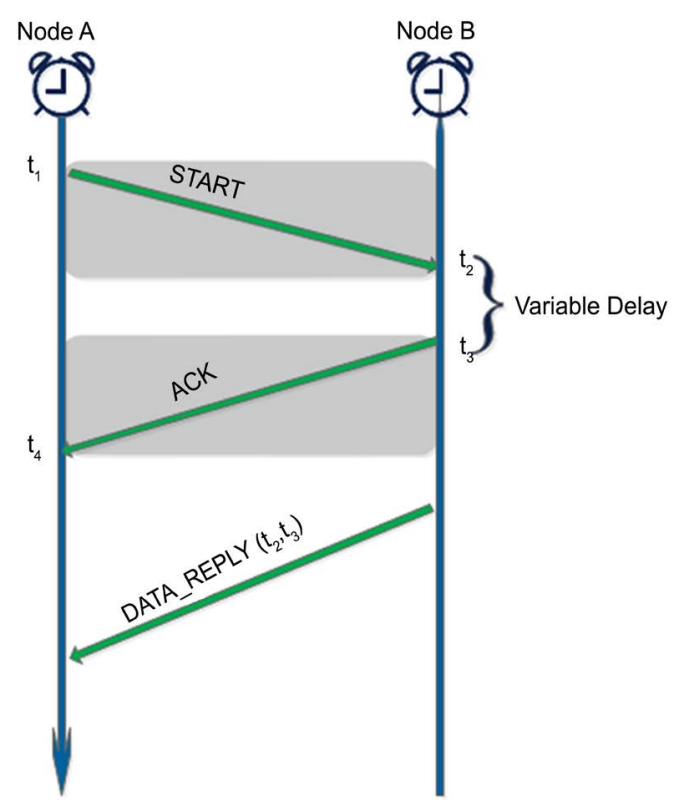

Figure 2. Ranging protocol session TWR_Skew.

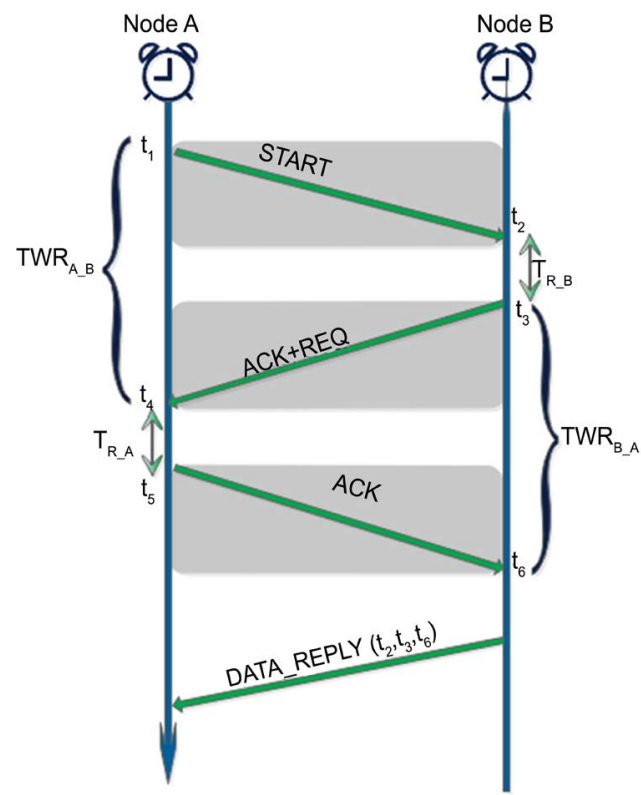

Figure 3. SDS-TWR protocol performing ToF measurement between two "asynchronous" nodes.

message containing the instants $t_{2}, t_{3}$ and $t_{6}$ of the node B. Calculations of flight time and distance are obtained by using Equation (6) and Equation (7).

$$
\begin{gathered}
\mathrm{ToF}_{\mathrm{SDS}-\mathrm{TWR}}=\frac{\left(t_{4}-t_{1}\right)-\left(t_{3}-t_{2}\right)+\left(t_{6}-t_{3}\right)-\left(t_{5}-t_{4}\right)}{4} \\
\text { Distance }=\mathrm{ToF}_{\mathrm{SDS}-\mathrm{TWR}} * C
\end{gathered}
$$

Because of the frequency shift at the nodes, the return times for the response of A and B are evaluated differently. An average of two "round trip" times of A 
and $\mathrm{B}$ will allow reducing the error induced ranging. This specificity of the protocol will therefore reduce the difference between the actual distance and that which will be measured by the SDSTWR protocol without completely eliminating it [8].

\section{Outdoor Measurements}

Often, simple analyses based on simulation software are enough to provide a result on the performance of a given system. However, these programs are based on too idealistic models that do not often consider the imperfections and physical realities of the material and the measurement environment.

When the system to be studied is a WSAN, the fact that these parameters are not considered may lead to a different operation from the deployment than that provided by the simulation software.

Thus, certainly, the best approach would be to perform analyses on real nodes (sensors and actuators) and in a real physical environment. This explains why our analysis approach is based on measurements with real nodes.

\subsection{Description of Measurement Equipment}

For the measurements, we use two DecaWiNo nodes: the first fixed and located at a height of $1.5 \mathrm{~m}$ from the ground, the second always at the same height is linked to a mobile pole. The pole here serves only to vary the distance between our two nodes. See Figure 4.

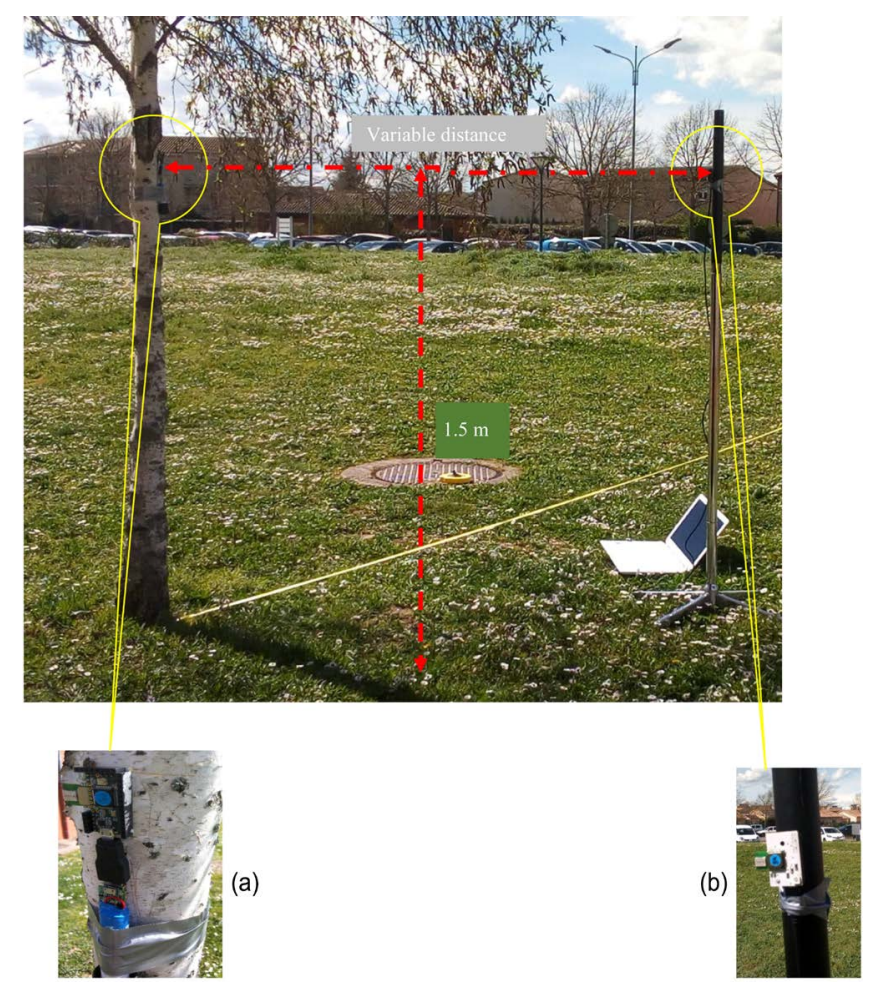

Figure 4. Principle of taking measurements. (a) Fixed DecaWiNo; (b) DecaWiNo carried by the mobile pol. 


\subsubsection{DecaWiNo Node}

DecaWiNo is part of the family of WiNo nodes (Wireless Node) [9] developed at IRIT by the RMESS team. The WiNo family is based on the Arduino environment and its components are developed in Open Hardware, allowing to setting up a wide variety of WiNos (see Figure 5). Table 1 summarizes the principal features of the developed WiNo nodes.

As we said earlier in this study, we will use DecaWiNo. This type of WiNo is composed of an Arduino board (Teensy 3.2) and the DecaWave DWM 1000 module with a UWB transceiver and an antenna. For node management, the DecaDuino library was developed by the RMESS team in the Arduino environment (Figure 6).

\subsection{Measurement Procedures}

For each of the three protocols, we carried out measurements on 19 points, and on each point 100 measurements were collected which makes a total of 5700 measurements.

Measurements are made in external environment, considering the two nodes in line of sight (LOS) and always starting for each protocol with a taking at 0.5 m.

After this, we start from $1 \mathrm{~m}$ to $5 \mathrm{~m}$ in steps of $1 \mathrm{~m}$. Then $5 \mathrm{~m}$ to $30 \mathrm{~m}$ in steps of $2 \mathrm{~m}$ and always pass by the point $20 \mathrm{~m}$.

\subsection{Measurement Results}

We present in the following sections the results obtained with the various protocols mentioned as well as their graphical representation.

\subsubsection{Ranging by TWR Simple}

We summarize in Table 2 the measurements made with the TWR protocol. However, with the number of takes made: 100 for each point, we will only give

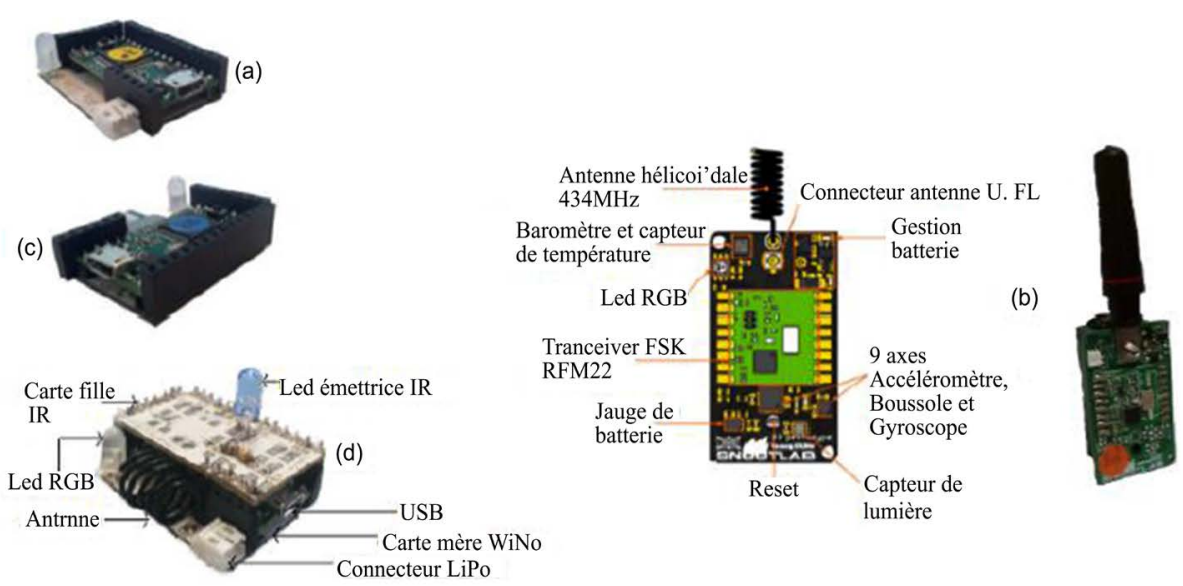

Figure 5. The WiNos nodes. (a) WiNoRF22; (b) TeensyWiNo; (c) DecaWiNo and (d) WiNoIR. 
Table 1. Characteristics of WiNos developed [8].

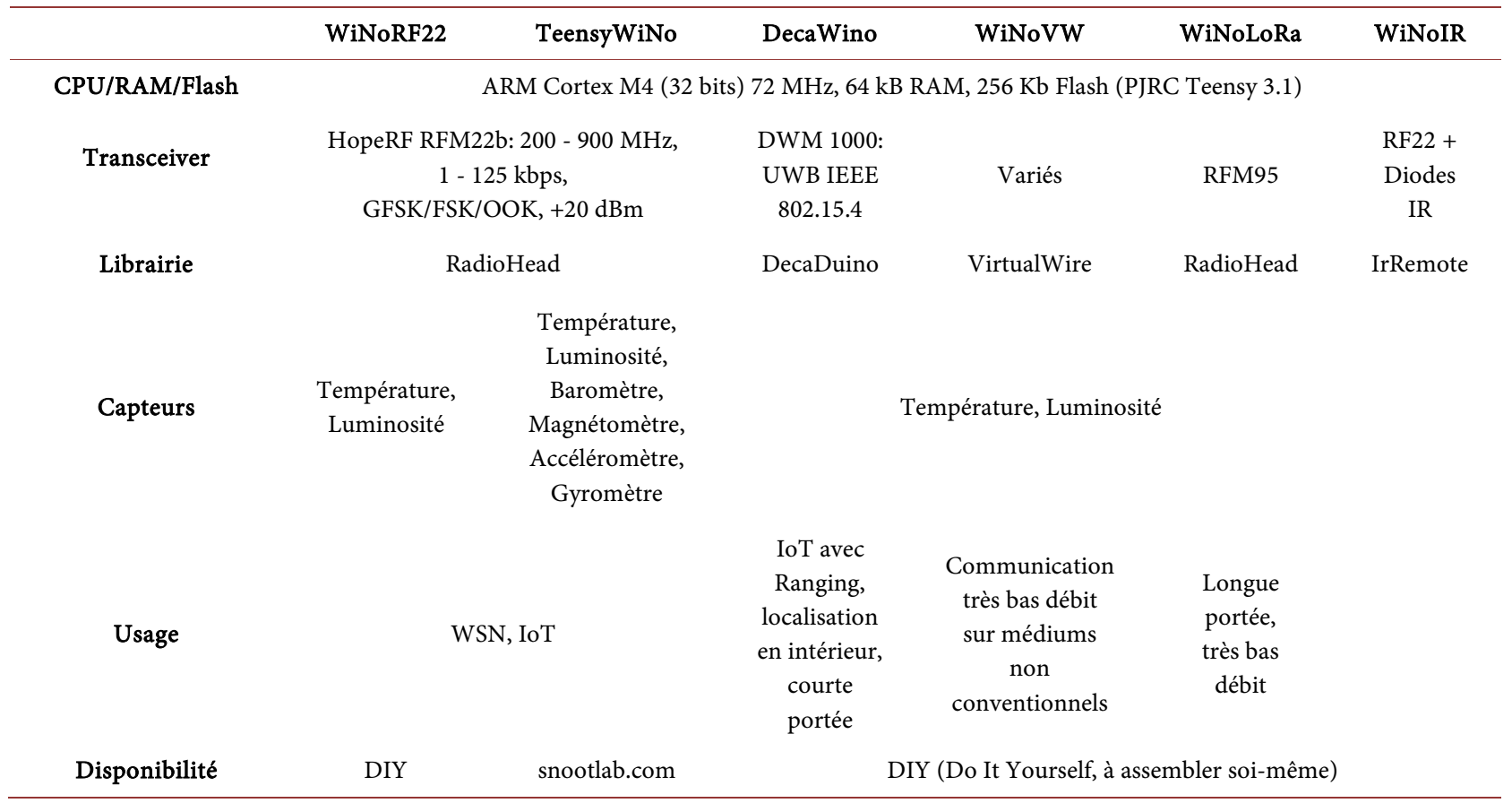

Table 2. Summary of TWR measures (m).

\begin{tabular}{|c|c|c|c|c|}
\hline Real Distance & Average distance TWR & Average error & Minimum Error & Maximum error \\
\hline 0.5 & 0.65 & 0.15 & 0.07 & 0.19 \\
\hline 1 & 1.19 & 0.19 & 0.15 & 0.23 \\
\hline 2 & 2.1591 & 0.1591 & 0.12 & 0.19 \\
\hline 3 & 3.14 & 0.14 & 0.09 & 0.2 \\
\hline 4 & 4.12 & 0.12 & 0.06 & 0.16 \\
\hline 5 & 5.20 & 0.20 & 0.16 & 0.25 \\
\hline 7 & 7.04 & 0.04 & -0.01 & 0.07 \\
\hline 9 & 9.00 & -0.00 & -0.05 & 0.03 \\
\hline 11 & 10.9481 & -0.05 & -0.1 & 0.03 \\
\hline 13 & 12.87 & -0.13 & -0.19 & -0.08 \\
\hline 15 & 14.72 & -0.28 & -0.33 & -0.23 \\
\hline 17 & 16.62 & -0.38 & -0.43 & -0.32 \\
\hline 19 & 18.47 & -0.53 & -0.57 & -0.48 \\
\hline 20 & 19.49 & -0.51 & -0.56 & -0.46 \\
\hline 22 & 21.48 & -0.52 & -0.56 & -0.48 \\
\hline 24 & 23.33 & -0.67 & -0.74 & -0.58 \\
\hline 26 & 25.21 & -0.79 & -0.84 & -0.71 \\
\hline 28 & 27.08 & -0.92 & -0.98 & -0.86 \\
\hline 30 & 28.89 & -1.11 & -1.18 & -1.05 \\
\hline
\end{tabular}




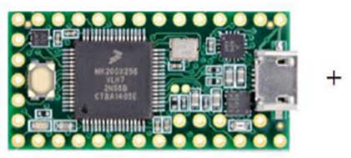

Teensy 3.2

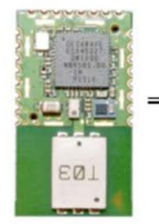

DWM1000

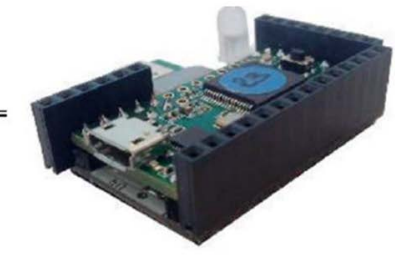

Deca WiNo

Figure 6. Components of DecaWiNo.

the average value measured by the TWR protocol for each point as well as the average, minimum and maximum errors.

The representation of the error according to the real distance (Figure 7) shows in a general way that the absolute average error varies from 0 to $1.10 \mathrm{~m}$ with extremums ranging from $1 \mathrm{~cm}$ to $1.18 \mathrm{~m}$ over a real distance of 0.5 to $30 \mathrm{~m}$. In particular, for real distances with less than $14 \mathrm{~m}$, the average error does not exceed $20 \mathrm{~cm}$ and the maximum error is $25 \mathrm{~cm}$. These average and maximum absolute errors are around $50 \mathrm{~cm}$ over distances between 14 and 22 meters. And for distances between 22 and 30 meters, these values are around 60 centimetres for the average value and 58 to 98 centimetres for the extremums. And finally, we find that the error committed by the TWR is greater than 1 meter for the real distances greater than or equal to 30 meters.

We also notice that for distances of less than 9 meters, the TWR overestimates the actual distance.

\subsubsection{Ranging by TWR_Skew}

Under the same conditions and measurement parameters as those of the TWR, we performed measurements with the TWR_Skew protocol. The results are summarized in Table 3 and graphically represented in Figure 8.

We note here that the average error varies generally from $20 \mathrm{~cm}$ to $1.5 \mathrm{~m}$ with absolute extreme values ranging from $37 \mathrm{~cm}$ to $1.63 \mathrm{~m}$ over real distances from 0.5 to 30 meters.

In particular, it can be seen on the one hand that for real distances of less than 13 meters the absolute errors (means and extremums) do not exceed $50 \mathrm{~cm}$. And on the other hand, that the absolute average error evolves rapidly from $50 \mathrm{~cm}$ to $1.50 \mathrm{~m}$ with absolute extremums of $60 \mathrm{~cm}$ to $1.63 \mathrm{~m}$ over distances between 13 and 30 meters.

We can also notice that with the TWR_Skew protocol, the actual distances are in general underestimates.

\subsubsection{Ranging by SDS_TWR}

Still in the same conditions as previously experiments with TWR and TWR_Skew protocols, we performed measurements with the SDS_TWR protocol. The results obtained are recorded in Table 4 and represented in Figure 9.

The average absolute error varies here from $20 \mathrm{~cm}$ to $1.30 \mathrm{~m}$ with extremums of $17 \mathrm{~cm}$ to $1.43 \mathrm{~m}$ over distances of 0.5 to 30 meters. 


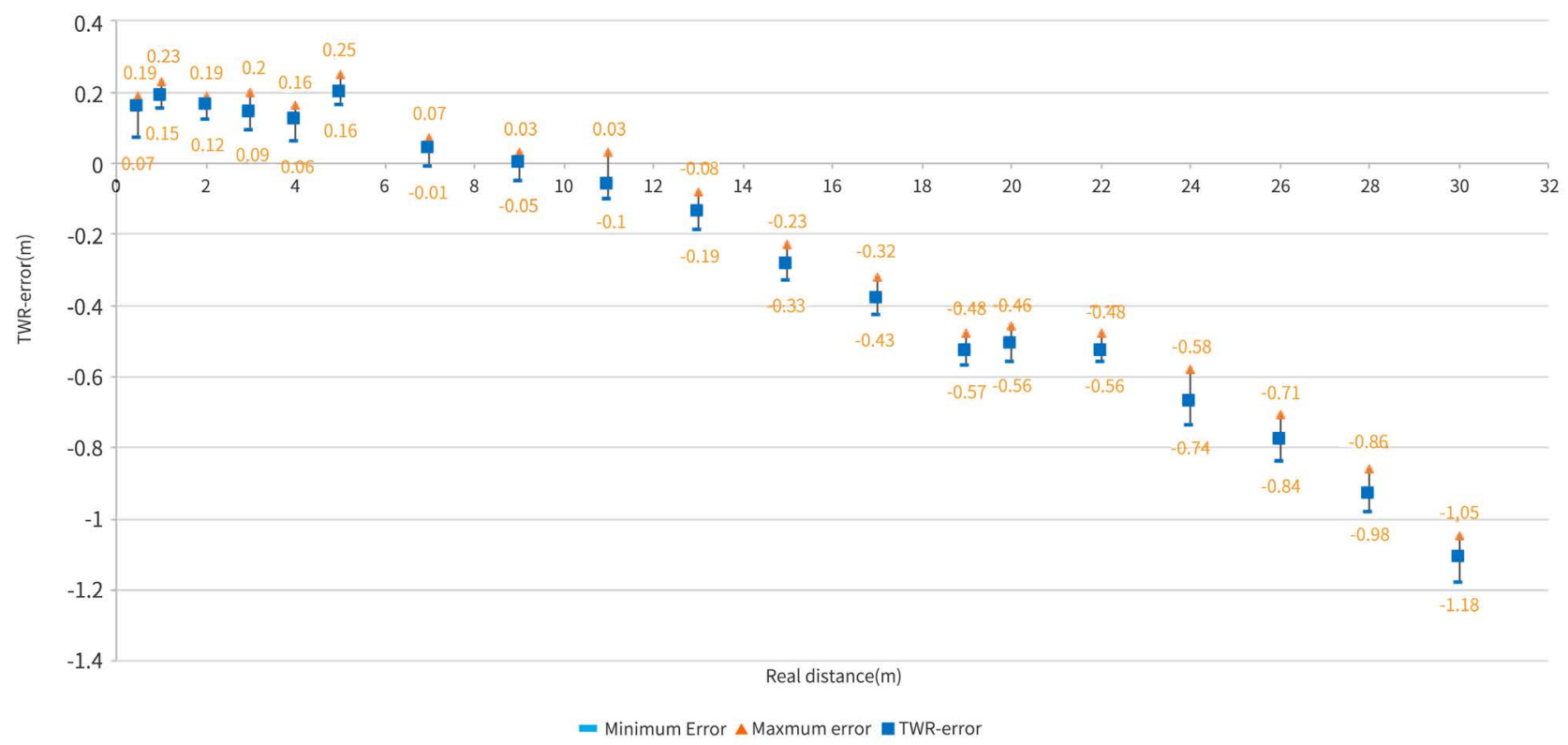

Figure 7. Representation of the TWR error depending the distance.

Table 3. Summary of TWR_Skew Measures (m).

\begin{tabular}{|c|c|c|c|c|}
\hline Real Distance & $\begin{array}{c}\text { Average distance } \\
\text { TWR }\end{array}$ & Average error & Minimum Error & Maximum error \\
\hline 0.5 & 0.26 & -0.24 & -0.31 & -0.19 \\
\hline 1 & 0.80 & -0.20 & -0.28 & -0.13 \\
\hline 2 & 1.7757 & -0.2243 & -0.34 & -0.15 \\
\hline 3 & 2.77 & -0.23 & -0.37 & -0.12 \\
\hline 4 & 3.76 & -0.24 & -0.33 & -0.13 \\
\hline 5 & 4.83 & -0.17 & -0.26 & -0.1 \\
\hline 7 & 6.66 & -0.34 & -0.43 & -0.26 \\
\hline 9 & 8.61 & -0.39 & -0.50 & -0.30 \\
\hline 11 & 10.6028 & -0.40 & -0.48 & -0.31 \\
\hline 13 & 12.48 & -0.52 & -0.60 & -0.44 \\
\hline 15 & 14.32 & -0.68 & -0.80 & -0.59 \\
\hline 17 & 16.26 & -0.74 & -0.86 & -0.63 \\
\hline 19 & 18.09 & -0.91 & -0.99 & -0.78 \\
\hline 20 & 19.11 & -0.89 & -1.00 & -0.81 \\
\hline 22 & 21.09 & -0.91 & -1.03 & -0.83 \\
\hline 24 & 22.94 & -1.06 & -1.23 & -0.92 \\
\hline 26 & 24.83 & -1.17 & -1.26 & -1.07 \\
\hline 28 & 28.50 & -1.32 & -1.46 & -1.18 \\
\hline 30 & 28.50 & -1.50 & -1.63 & -1.36 \\
\hline
\end{tabular}

As for the TWR_Skew, we also note that for distances less than 13 meters the absolute errors (means and extremums) do not exceed $50 \mathrm{~cm}$. Beyond 13 meters, 


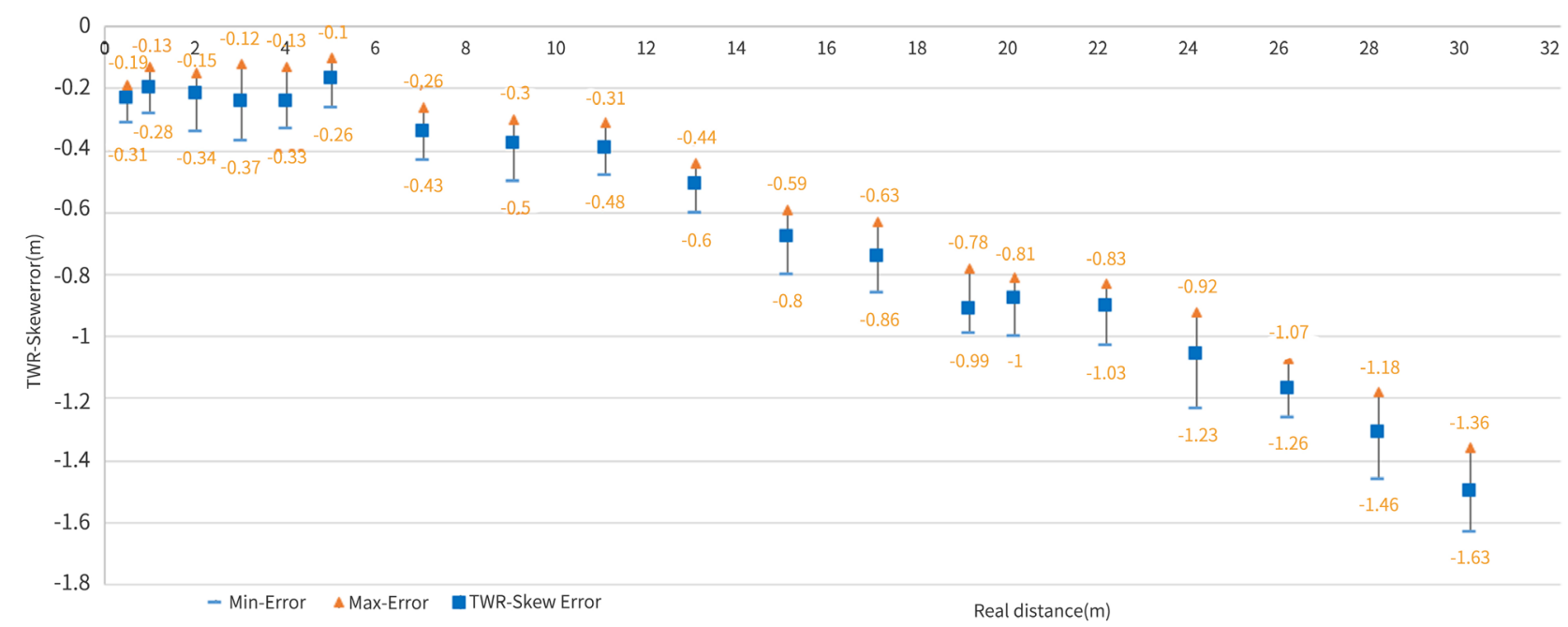

Figure 8. Representation of TWR Skew error depending on the distance.

Table 4. Summary of SDS-TWR measurements (m).

\begin{tabular}{|c|c|c|c|c|}
\hline Real Distance & $\begin{array}{c}\text { Average distance } \\
\text { TWR }\end{array}$ & Average error & Minimum error & Maximum error \\
\hline 0.5 & 0.29 & -0.21 & -0.25 & -0.17 \\
\hline 1 & 0.76 & -0.24 & -0.27 & -0.21 \\
\hline 2 & 1.7743 & -0.2257 & -0.26 & -0.19 \\
\hline 3 & 2.76 & -0.24 & -0.28 & -0.19 \\
\hline 4 & 3.74 & -0.26 & -0.3 & -0.21 \\
\hline 5 & 4.67 & -0.33 & -0.36 & -0.3 \\
\hline 7 & 6.64 & -0.36 & -0.39 & -0.33 \\
\hline 9 & 8.57 & -0.43 & -0.47 & -0.39 \\
\hline 11 & 10.5078 & -0.49 & -0.56 & -0.38 \\
\hline 13 & 12.43 & -0.57 & -0.62 & -0.53 \\
\hline 15 & 14.32 & -0.68 & -0.71 & -0.64 \\
\hline 17 & 16.22 & -0.78 & -0.82 & -0.73 \\
\hline 19 & 18.11 & -0.89 & -0.92 & -0.86 \\
\hline 20 & 19.09 & -0.91 & -0.94 & -0.85 \\
\hline 22 & 20.94 & -1.06 & -1.10 & -1.03 \\
\hline 24 & -22.97 & -1.04 & -1.15 & -0.87 \\
\hline 26 & 24.68 & -1.32 & -1.43 & -1.21 \\
\hline 28 & 28.63 & -1.25 & -1.30 & -1.19 \\
\hline 30 & 28.63 & -1.37 & -1.42 & -1.31 \\
\hline
\end{tabular}

these absolute average errors evolve rapidly from $55 \mathrm{~cm}$ for a real distance of 13 meters to $1.35 \mathrm{~m}$ for a real distance of 30 meters, with extremums ranging from $53 \mathrm{~cm}$ to $1.43 \mathrm{~m}$ respectively. The SDS-TWR protocol always gives an underestimated value of the real distance. 


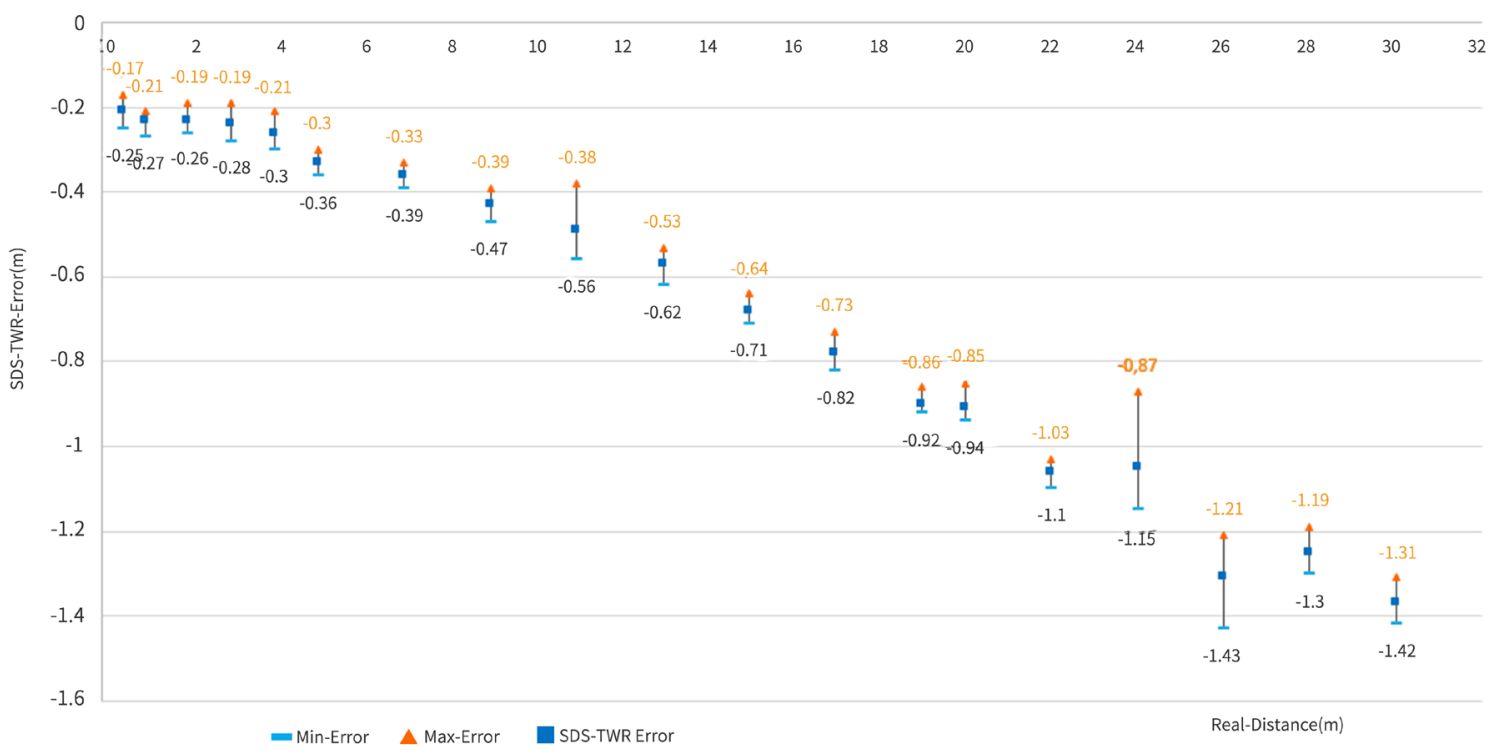

Figure 9. Representation of SDS_TWR error depending on the distance.

\subsection{Discussion}

The observation of the average errors shows that the errors made by the TWR_Skew and SDS_TWR protocols are quite close. Even though the TWR_Skew error is slightly smaller for distances less than 28 meters, the error committed by these two protocols exceeds $50 \mathrm{~cm}$ for the real distances greater than 13 meters.

On the other hand, for the TWR protocol, the error made here is much smaller, going up to an absolute distance of $50 \mathrm{~cm}$ from that made by the TWR_Skew protocol. In addition, for this protocol, the error does not exceed 50 $\mathrm{cm}$ for distances less than or equal to 22 meters (see Figure 10). This result obtained with the TWR protocol seems very interesting especially for applications where the distance between the nodes does not exceed 22 meters and a precision of the order of $20 \mathrm{~cm}$ (for distances less than 14 meters) or $50 \mathrm{~cm}$ maximum (for distances between 14 and 22 meters).

Thus, given the number of measurements taken per point, we can say that comparatively the TWR ranging protocol is better than the TWR_Skew and SDS_TWR ranging protocols in outdoor; even though these last two protocols have been established to correct the mistakes of TWR. But the validation tests of the correction of TWR errors by the TWR_Skew and SDS_TWR have been done until then in indoor environment with a lot of reflections because of the walls and ceiling, and low ranges not exceeding 10 meters.

\section{Conclusion}

In this paper, we have implemented three ToF ranging protocols (TWR, TWR_Skew and SDS-TWR) on DecaWiNo nodes incorporating UWB technology. These nodes allowed us to make ranging measurements whose graphical 


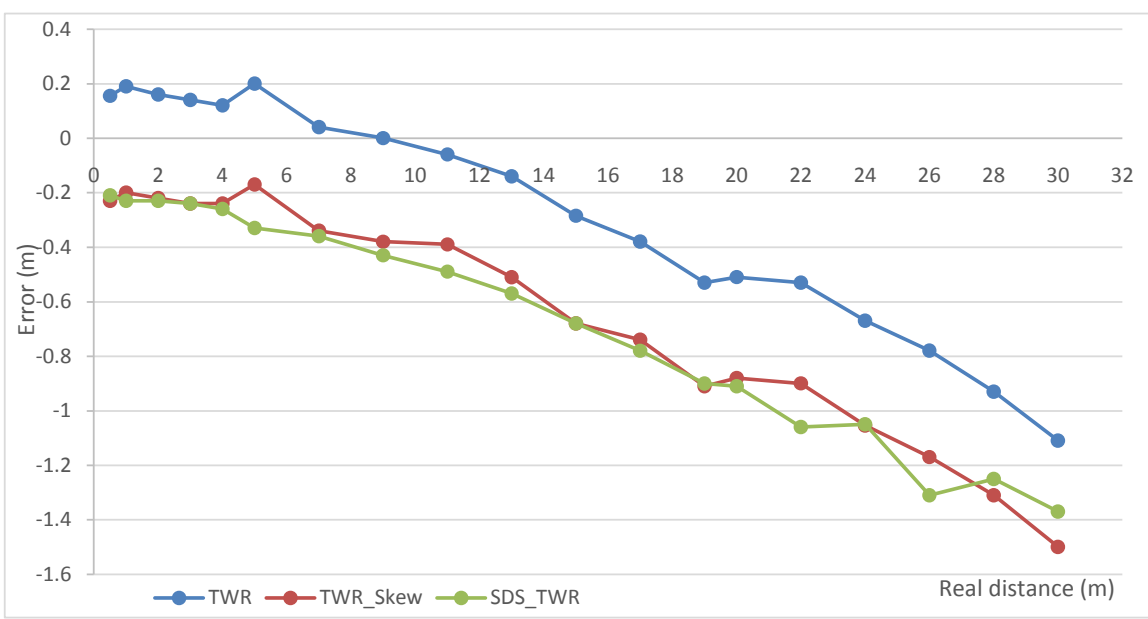

Figure 10. Error representation of different protocols depending on the real distance.

interpretation allowed to showing the individual performances of the various protocols.

These performances offer us several perspectives, first of all on the integration of the TWR protocol on our application whose maximum distance between nodes is 20 meters; since this protocol is the one that better estimates the distance between nodes among the three studied in this document. But also, perspectives on the search for mechanisms that can help reduce the error committed by the TWR protocol, as well as the study of the impact of the error made by this protocol on the accuracy of mobile target location algorithms.

\section{Acknowledgements}

The authors would like to thank CEA-MITIC of the UFR SAT at the University Gaston Berger of Saint-Louis/Senegal for his financial support for the travel to Toulouse (in France) and the publication of this work.

\section{Conflicts of Interest}

The authors declare no conflicts of interest regarding the publication of this paper.

\section{References}

[1] Kobenan IgnaceKossonou (2014) Étude d'un système de localisation 3-D haute précision basé sur les techniques de transmission Ultra Large Bande à basse consommation d'énergie pour les objets mobiles communicants. Electronique Université de Valenciennes et du Hainaut-Cambrésis, Valenciennes.

[2] Fofana, N.I., Van Bossche, A. and Val, T. (2014) Etude des couches MAC dédiées à l'UWB. Journées Nationales des Communications Terrestres-JNCT 2014, Toulouse, France, 8-19.

[3] Jacquot, A., De Sousa, G., Chanet, J.P. and Pinet, F. (2011) Réseau de capteurs sans fil pour le suivi de l'humidité du sol des vignes. ECOTECHS' 2011, Capteurs et systèmes de mesures pour les applications environnementales. Montoldre, France. 
[4] LópezRiquelme, J.A., Soto, F., Suardíaz, J., Sánchez, P., Iborra, A. and Vera, J.A. (2009) Wireless Sensor Networks for Precision Horticulture in Southern Spain. Computers and Electronics in Agriculture, 68, 25-35.

https://doi.org/10.1016/j.compag.2009.04.006

[5] Mallamaire, L. (1961) La lutte contre les oiseaux granivores en Afrique Occidentale (Mauritanie, Sénégal, Soudan, Niger). Journal d Agriculture Tropicale et de Botanique Appliquée, 8, 141-179. https://doi.org/10.3406/jatba.1961.6911

[6] Fofana, Nezo Ibrahim, Van den Bossche, Adrien, Dalce, Rejane and Val (2016) Thierry Prototypage et analyse de performances d'un système de ranging pour une localisation par UWB. 16 éme Colloque Francophone sur P Ingénierie des Protocoles (CFIP2015), Paris, France, 22-24 July 2015, 1-8.

[7] Kara, M. (2009) Réseau de capteurs sans fil: étude en vue de la réalisation d'un récepteur GPS différentiel à faible coût. Réseaux et télécommunications [cs. NI]. Université Blaise Pascal-Clermont-Ferrand II, Clermont-Ferrand.

[8] Ibrahim, F.N. (2017) Contribution aux architectures protocolaires pour un système de localisation dans un réseau de capteurs sans fil basé sur une couche physique 802.14.4a UWB. Université Toulouse Jean-Jaurès, Juillet.

[9] http://wino.cc//decawino 